\title{
sciendo
}

\section{Forced digitization due to the global pandemic}

\author{
Ștefan Marian DUMITRU \\ Bucharest University of Economic Studies, Bucharest, Romania \\ stefan.dumitru91@gmail.com
}

\begin{abstract}
COVID-19 has produced dramatic consequences on the world economy, industry, and citizens. But digitization is also aiding many businesses to adapt and surmount the current situation caused by the pandemic. The increase in the utilization of technology in the everyday lives of people and businesses to cope with this exceptional state is a testimony of the digital acceleration process. This study examines the impact of the digital revolution processes in three areas: labor and social interactions, marketing and sales, and technology. The effect of digitalization is anticipated to be transversal to each domain and will inspire the emergence of new digital services and products centered on flexibility. Furthermore, new methods of working will encourage the demand for new talent irrespective of people's geographical position. Furthermore, cybersecurity and privacy will grow to be two key components that will support the integrated growth of artificial intelligence, robotics, big data, and the Internet of Things technology.
\end{abstract}

Keywords: COVID-19, EU, Coronavirus, Digital transformation, Workforce.

\section{Introduction}

The COVID-19 pandemic has been confronting companies in various areas of occupation. Many of these businesses have been compelled to adopt new internal working habits and sensed a strong pressure to provide products through digital outlets. Enterprises have undergone profound changes and within a short time frame implemented solutions centered on digital technologies. During the same period, it has become crucial to reshape management and partnership models to ensure that no one within companies is left behind and feels barred from this digitization process. Berger (2020) states that a crucial component for the triumph of teamwork in COVID-19 time is the presence of all team members in the firm's major trials. However, this process has inevitably become more complex, as the stream of information that naturally emerged in the same physical space is now developing into a challenge to get everyone in a nimble and effective way. Digital transformation is described by the fusion of advanced technologies and the incorporation of digital and physical systems. Groundbreaking business models, innovative production processes, and the formation of knowledge-based services and products abound, according P.C Verhoef (2020). Even though digitization is not a new occurrence, the trials and opportunities that are linked are constantly shifting. Before the beginning of COVID-19, the challenges posed to digital transformation were effectively concentrated on the fourth industrial revolution, linked with the notions of Internet of Things (IoT), Industry 4.0, and Web 4.0, according to Almeida and Fonseca (2018). The challenges concerned both the disruption of ideas and technologies, as well as the swiftness of this digital transformation. In the age of COVID-19, the challenges were uncovered, and it is vital to involve the entire company and stakeholders in this development. Moreover, the rate with which this change followed was incredible. Businesses had to do this irrespective of their previous plans and knowledge in digital transformation processes.

\section{Methodology}

Unavoidably, organizations will shift along the route of digital transformation. Yet, a key matter is whether they are ready for this change. Studies according to Matt and Rauch (2020), suggest that 
companies, even those that are most advanced in the digital transformation of their endeavors and workflow, are not yet entirely primed to face the trials of the digital transformation. Digitization needs a reorganization of procedures, turning the company nimbler, providing in more organic structures, strengthening standardization and automation, in a bid to improve the response capability to clients. COVID-19 has created difficult and uncertain times and hastened the unavoidable processes of digital transformation. At this point, it is vital to start contemplating the post-COVID-19 world and, beyond all, to investigate how we can influence and transform these challenges into new opportunities, equally in business and internal organization. In this logic, this study seeks to discover the challenges and opportunities that will be created by the digitization of company's activities, contemplating three important domains of their business: (i) marketing and sales; (ii) labor; and social relations and (iii) technology. These areas were selected because of the solid impact that Ban (2020) and Hasanat et al. (2020) forecast will have on the actions of businesses developing from COVID-19. This work applies the action research method to comprehend the questions posed by COVID-19 to these three key areas. This research paradigm is suitable where significant proximity to researchers is required, and the frontiers of research are not inflexible.

\section{Results and discussions \\ Social and labor relationships}

Social and labor relationships have undergone substantial transformations in the time of COVID-19. Throughout the quarantine period, citizens had to adjust to a teleworking model and discover how to share a diminished space with their families. Residences became hybrid spaces where household responsibilities and office labor are shared. This situation has a significant impact on people's lives, with the danger of having their revenue diminished or suffer the loss of their jobs. According to Riley (2020), 60 million Europeans remain in danger of losing their employment or getting their monthly incomes cut because of COVID 19. This whole situation epitomizes both a social and economic tragedy.

The social and labor transformations brought about by COVID-19 have not only speeded up the processes of digital transformation but have also aggravated the social gap between the classes, according to Milanesi (2020). Not all businesses and people have the same funds to confront the challenges of digital transformation. The level of the dematerialization of responsibilities and services differs on the nature of each commercial activity. It appears obvious that smaller companies, particularly micro companies, and in areas of activity deeply affected by COVID-19 (expl. Clothing, restaurants, and tourism) are especially affected. According to the Romanian National Anti-Fraud Association, the tourism, lodging, and restaurant sectors decreased by $60 \%, 37 \%$ and $33,5 \%$ in 2020 , according to Milanesi (2020) Information from the National Statistics Institute (NSI) corroborate these discoveries and add the transportation and storing sector. On the opposite side, food, and utilities were less affected. Additionally, of note is the rise in the consumption of technological products.

The quick and unforeseen digitization process, forced by COVID-19, is triggering a sense of incapacity in organizations to draw the talent required to face the future, as stated by L. Dahlander and M.Walin, (2018) Although, Maresova et al. (2018) point the part industry 4.0 will play in shaping the international business environment, people and their services will continue to be at the center of economic activity. Consequently, the digital economy can only work if it is escorted by a strategy between the public and private sectors, for the digitalization of education and teaching, both at the level of cross knowledge that the whole populace will require to have in 
communication and information technologies, as well as in the preparation of highly specialized individuals in the areas of computer science. It is then feasible to deduce that a solid commitment to digitalization does not automatically mean a disinvestment in human resources. The opposite is true, it is essential to employ and administer the talent of the most skilled and appropriate people for the fresh challenges of the digital economy. Appropriately, this requirement may lead to a shift in the education offered at different levels of education, which may necessitate reorganizing current programs and/or expanding short courses. These programs should offer very specific skills in several areas, including technology, but without neglecting responses to social challenges, as well as interpersonal relations, that employees will feel in the post- COVID-19 era. One of the possible responses is to promote the advancement of vocational training in close partnership with employers, both private and public entities, by promoting the expansion and specialization of the educational offer. It is tricky to describe the prerequisite profile of the labor force in the postCOVID-19 era. The digital transformation of businesses upholds the increasing importance that data science, digital marketing, and cybersecurity may take in corporations. Aligned to these dimensions, it will be essential to apply methodological expertise and creativity to transmute data knowledge into technologically viable business models that merge security with economic possibility. Unlike in the industrial revolution, Saracco (2018) states that in this development of digital transformation, production increase is disconnected from job creation and revenue since it materializes fundamentally from the conception of new types of products/services and reformulation of systems. Ultimately, with the inevitable increase in teleworkers, even though implementing a hybrid model, it will contribute to the sustainable advancement of cities as more citizens look outwork to living in the suburbs or smaller, cheaper cities, it is likely that many employees that left their expensive rented apartments will never come back. The environmentally friendly dimension, which has considerably suffered from globalization, may benefit, according to Figge, Oebels and Offermans (2017). Not all workers will need to be residing in or around cities, which will result to reduce car traffic and enhance the quality of life of the citizens. For this to occur, there must be no regional unevenness in the digitalization process, particularly in access to data networks, which may create a digital fracture between countries. Moreover, in a post-COVID-19 world, technology should help to develop countries that are currently economically disadvantaged, participating in this way to reduce asymmetries.

\section{Sales and marketing}

The digital technologies and the transformation they have brought in the everyday lives of businesses have created new economic prospects. They launched new markets for new types of products and have altered entire industries, dematerializing the goods that had been marketed, Tachinger, Rauter, Muller, Vorraber and Schirigi (2019). At this stage, the digitization of the economy must offer very personalized products at substantially lower costs. With improvements in technology and the continuous presence of the Internet in the everyday routine of citizens, the use of digital goods is developing a valid substitute to physical products. They offer high availability since they can be utilized and consumed from everywhere. Examples of such products and services consist of on-demand streaming, e-books, and applications. The COVID-19 pandemic had a substantial impact on the expansion of e-commerce, mainly powered by trade and mobility restrictions and will continue to do so, with an estimated increase of $15 \%$ in sales for e-commerce platforms in Romania, as pointed out by Agerpres (2021). This movement might have a broader scope and coverage. Kleunder et al. (2019) states that the dematerialization of processes will add to substantially decrease some fixed costs for businesses. In parallel, the younger generations will 
embrace their own habits of consumption of products and services in the digital era with less physical contact and more in the digital environment. The plasticity of the new digital products and services is a deciding factor for their implementation, as shown by Lyytinen, Yoo and Boland (2016). In this logic, providing consumers with options or models that are flexible to their requirements, leads to a faster acquisition outcome. There are several types of commissioning for each business, but it is likely that in the future the customer will give first choice to those models in which they have the independence to choose and develop their service or product, with no need for physical and time-consuming intermediation. Simplification is avital route to a superior customer experience and integration is just as crucial, both to streamline the relationship with the customer and to utilize data wisely.

The launch of new technologies in managerial processes not only facilitates to build customer loyalty but also helps to achieve new audiences in the international marketplace, according to Banalieva and Dhanaraj (2019). Digitization enables companies to setup their operations anywhere in the world, particularly through faster communication and joint services. In parallel, business interaction with public services will also move strongly to digital platforms in international, national, and local government.

\section{$R \& D$ practices will also transform}

In the technological and industrial sectors, the advancement of innovation is an important factor for the advancement of new competitive advantages, as stated by Fransman (2018). In a global framework of competitiveness, Brown et al. (2020), claims that open innovation and cooperative innovation have been creating visible results of added value for the market. These examples are based on the distribution of investments, skills, and risks. Companies can only understand the added value of these innovation models with a robust focus on cooperative technologies that allow the creation and distribution of knowledge in a cooperative way among the different economic players.

The supply chain management in the view of inbound goods, but especially in the output to continue sales, endured a great deal of stress during the lockdown, and will probably be even greater to ensure the success of companies that are investing in e-commerce, as stated by Ziarul Fianciar (2021). The most urgent need is for the incorporation and automation between the various actors (salesperson and distributor), particularly on platforms that facilitate the salesperson to obtain the best price, and the distribution of their product can lead to the advent of new business models.

In turn, the payment systems business standard, which for some small companies has been an obstacle to the advancement of new business, will tend to have an expansion in turnover. In 2020, due to the increase in e-commerce, the Romanian electronics payment market grew by $36 \%$ and it is estimated that in 2021 it will continue to grow by another $15 \%$, according to Ziarul Financiar (2021). This may support the emergence of new players and, therefore, greater negotiating power for businesses that choose to move in the direction of new marketing channels, especially on social networks. An example of this is Fintech, with strong growth in all types of digital financial services, according to a joint study by the World Bank, the Cambridge Centre for Alternative Finance at the University of Cambridge's Judge Business School, and World Economic Forum. Fintech has demonstrated its capability to close gaps in the supply of financial services to families and companies in emerging markets and developing economies. 


\section{Technology}

Digital transformation depends on the personnel and the methods at their disposal. Technology plays a crucial role in the digital shift. There is an array of developing technologies that have already added to the digital transformation of many firms and industries, but in a post-COVID-19 world will assume they will have a greater role.

The IoT is the network of physical good that includes technologies and software that allows them to speak and interact intelligently internally or externally, with environment, over the Internet. IoT can have uses in various domains from business, personal, and industrial. According to Maple, IoT has the capability to upset the realities of businesses and lead to substantial operational enhancements, offering new types of customer services to customers and high-quality goods. The accessibility of data and knowledge, through the monitoring and measurement of all activity of users, allows the IoT to utterly transform the vision and perception of the action, generating numerous benefits and a more detailed and real understanding of the business. This data has been essential to overcome the challenges and difficulties presented to companies by the proliferation of COVID-19.

As a result of the improvements of IoT and the growth in the volume of data available to businesses, there is a need to find new methods to analyze the high volume of diverse information that has arisen. Big Data is the phrase that can be applied to refer to this extremely broad set of data, which, therefore, requires special tools to be stored, extracted, organized, and transformed into information that can be studied extensively and in a small amount of time. The capacity to capture significant volumes of data and examine it correctly and effectively has developed many times in recent years due to the development of more advanced algorithms and the continuous development of power and computational capacity. But, in a post-COVID-19 world, significant expansion in the volume of data on the Internet is anticipated and the utilization of big data expertise and techniques will be vital for a business's survival. A shift in the big data paradigm is anticipated as a component of establishing a viable advantage for a new paradigm in which big data is a determining factor for the survival of businesses in a gradually wider set of industries. At this level, an exponential increase in the use of bigdata is expected to project sales of products or services, to forecast consumer behavior, to evaluate consumer trajectory in physical and virtual spaces, and to detect computational security risks.

Robotics is another domain that is expected to grow considerably. Robots will be gradually used not only to replace human work but also to cooperate with humans, according to Webster and Ivanov (2020). Indeed, robots are even now being used to solve intricate tasks, but their utility and usability will evolve. Robots are projected to be gradually more independent, adaptable, and cooperative. As a result, robots will be able to work together with other robots as well as work alongside humans, and safely learn from them. Industry 4.0 offers a high possibility for growth not only in robotics, but also in the digital interconnection between the supply chain, the means of production, and the distribution channels.

As digital technology infiltrates society and the economy, its weaknesses also grow. It is essential to protect cyberspace from events, malicious activity, and abuse. Nevertheless, cybersecurity incidents, whether deliberate or unintentional, are growing at a disturbing rate and can interrupt both business operations and essential services (e.g., water, electricity, health). According to Martins, the difficulties related to cybersecurity can cause fear in the acceptance of new digital technologies by businesses, can be ordered in three major groups: (i) lack of mindfulness and information on the subject; (ii) existence of intricate scenarios where obsolete 
technologies cohabit with developing technologies; and (iii) lack of time and capital to invest in cybersecurity.

In a post-COVID-19 world, it is likely that there will be substantial shifts in the awareness of companies about cybersecurity. From one point of view, understanding on the subject will necessarily improve, but from a different viewpoint, we will have an increasing heterogeneity of equipment linked to the internet, that will increase these dangers. Several of these dangers can only be alleviated with significant efforts in the preparation of people, as a large part of cybersecurity hazards are related to neglectful human behavior. Customers will be much more engaged and worried about cybersecurity threats and will require technologically innovative solutions that do not endanger the security of their personal data.

\section{Conclusion}

The consequences and pace of technological interference in companies are growing and have been exacerbated by COVID-19. Businesses need to be ready for this task, and to this end, they must foster a philosophy of innovation that includes the company's employees in this process. COVID-19 has accelerated the processes of digitalization not only in businesses but also in people and public entities. The enormous task for managers is to get engaged in this change, while attempting to keep the business growing, facing a different and unsure future. Moreover, it is important to highlight that the three crucial aspects related to labor/society, market/sales, and technology are strongly interrelated. Digitization of companies will expand the importance given to the digital networks of marketing and sales of companies. It will also promote teleworking and utilization of technological products as more individuals will interact using hybrid communication methods accessible from anywhere, and not solely in the physical environment of companies and their homes.

The study explored the effect of digitization on labor and social relations, marketing and sales, and technology dimensions. The effects of digitization are being sensed throughout all these areas. The success of a company's digital transformation processes will vary heavily on the implementation of the community, namely its employees, partners, suppliers, and customers. Amongst the confronted challenges is the implementation of telework and a distance working model that allows high cooperation and interactivity, in which the talent overpowers the geographical location of these people. The expansion of e-commerce is an additional challenge, since associated with it develops a whole value chain that must be appropriately incorporated to provide a distinguished shopping experience for the customer. The flexibility of digital products and services will similarly be a deciding factor for its acceptance. On the technological side, the development of artificial intelligence, IoT-supported systems, robotics, and big data emerges. Additionally, privacy and cybersecurity will also be an important element in the acceptance of new technological solutions.

This research primarily presents practical contributions by studying an evolving theme with high interest from citizens and businesses. This study also has several limitations. First, now of this study, COVID-19 is still far from being diminished, and only very recently some countries have reimplemented restrictions on business activity and travel, even with vaccines being offered. For many businesses, the long-term impacts of COVID-19 may turn their business activity unviable. In future studies it would be attractive to explore the effects of COVID-19 with an empirical study with the business sector, to collect feedback from businesses on their future for digitization. 


\section{References}

Almeida, F. (2017). Concept and dimensions of web 4.0, Int. J. Comput. Technol, 16(7), $7040-7046$.

Ban, X. (2020). Responding to the impact of COVID-19 on labor relationship in China, Cielo Laboral, http://www.cielolaboral.com/wpcontent/ uploads/2020/04/china_noticias_cielo_ coronavirus.pdf.

Banalieva, E. R., and Dhanaraj, C. (2019). Internalization theory for the digital economy. J. Int. Bus. Stud., vol. 50, 1372-1387.

Berger, R. (2020). Digital workplace in the era of COVID-19. Roland Berger, Retrieved from https://www.rolandberger.com/en/Point-of-View/Digitalworkplace- in-the-era-of-Covid19.html.

Comerţul online va creşte cu cel puţin 15\% în România. (2021). Agerpres, Retrieved from: https://www.agerpres.ro/economic-intern/2021/02/21/comertul-online-va-creste-cu-celputin-15-in-romania-in-2021-analiza--665198.

Dahlander L., and Walin, M. (2018). The barriers to recruiting and employing digital talent. Harward Business Publishing, Retrieved from https://hbr.org/2018/07/the-barriers-torecruiting-andemploying-digital-talent.

Figge, L., Oebels, K., and Offermans, A. (2017). The effects of globalization on ecological footprints: An empirical analysis, Environ, Develop Sustainability, vol. 19, 863-876.

Fonseca, L. M. (2018). Industry 4.0 and the digital society: Concepts, dimensions and envisioned benefits," in Proc. 12 ${ }^{\text {th }}$ Int. Conf. Bus. Excellence, 585-590.

Fransman, M. (2018). Innovation Ecosystems: Increasing Competitiveness, Cambridge, U.K., Cambridge Univ. Press.

Hasanat, M.W., Hoque, A., Shikha, F.A., Anwar, M., Hamid, A.B., and Tat, H.H. (2020). The impact of coronavirus (COVID-19) on E-business in Malaysia, Asian J. Multidisciplinary Stud., 3(1), 85-90.

Klunder, T., Dorseln, J.N., and Steven, M. (2019). Procurement 4.0: How the digital disruption supports cost-reduction in procurement, Production, vol. 29, 1-11.

Lyytinen, K., Yoo, Y., and Boland, R.J. (2016). Digital product innovation within four classes of innovation networks, Inf. Syst. J., 26(1), 47-75.

Maresova, P. et al. (2018). Consequences of industry 4.0 in business and economies, Economies, 6(46), 1-14.

Matt, D.T., and Rauch, E. (2020). SME 4.0: The role of small- and medium-sized enterprises in the digital transformation, Palgrave Macmillan, 3-36.

Milanesi, C. (2020). Digital transformation and digital divide post COVID-19, Forbes, Retrieved from https://www.forbes.com/sites/carolinamilanesi/2020/05/11/digital-transformationand-digital-divide-post-covid-19/\#6b142e8a1656.

Pearce, G. (2020). Digital transformation? Boards are not ready for it!, Isaca, Retrieved from https://www.isaca.org/resources/isaca-journal/issues/2018/volume-5/digital-transformati on-boards-are-not-ready-for-it.

Rachinger, M., Rauter, R., Muller, C., Vorraber, W., and Schirgi, E. (2019). Digitalization and its influence on business model innovation, J. Manuf. Technol. Manage., 30(8), 1143-1160.

Riley, C. (2020). 60 million Europeans could suffer furloughs, layoffs, or wage cuts, CNN, Retrieved from https://edition.cnn.com/2020/04/19/business/europe-jobs-coronavirusmckinsey/index.html. 
Romanian Government (2020). Ordonanță de urgență $n r$. 224, Retrieved from http://legislatie. just.ro/Public/DetliiDocument/235872.

Saracco, R. (2018). Digital transformation vs. jobs. IEEE Future Directions, Retrieved from https://cmte.ieee.org/futuredirections/2018/11/29/digitaltransformation-vs-jobs/.

Verhoef, P.C. et al. (2019). Digital transformation: A multidisciplinary reflection and research agenda, Science Direct, Retrieved from https://www.sciencedirect.com/science/article/ pii/S0148296319305478.

PICBE |

Ziarul Financiar (2021). Piaţa locală de e-commerce va ajunge la minim 8 miliarde de euro în 2021, Retrieved from https://www.zf.ro/business-hi-tech/payu-piata-locala-de-e-commer ce-va-ajunge-la-minim-8-miliarde-de-19939613. 